\title{
Adult patient with Becker dystrophy undergoing orthopedic surgery: an anesthesia challenge
}

This article was published in the following Dove Press journal: International Medical Case Reports Journal

\author{
Masoud Parish \\ Haleh Farzin \\ Anesthesiology Department, Tabriz \\ University of Medical Sciences, \\ Shohada Teaching Hospital, Tabriz, Iran
}

\begin{abstract}
Muscular dystrophies are considered to be a series of neuromuscular diseases with genetic causes and are characterized by progressive muscle weakness and degeneration of the skeletal muscle. The case of an adult man with Becker dystrophy referred for repair of the patella tendon tearing and patella fracture is described. He underwent successful surgery using total intravenous anesthesia without any complications.
\end{abstract}

Keywords: Becker dystrophy, orthopedic surgery, adult, intravenous anesthesia

\section{Introduction}

Becker dystrophy (BD) is an inherited congenital muscular disorder manifested by incremental muscle loss and variable (ie, severity and distribution) weakness. To date, there is no cure for this chronic disease. ${ }^{1} \mathrm{BD}$ can be inherited in an X-linked manner, and in $\sim 60 \%$ of $\mathrm{BD}$ cases, its cause is correlated with deletion mutation, resulting in the absence of dystrophin. ${ }^{2} \mathrm{BD}$ has a lower incidence and a milder disease course than other musculoskeletal disorders, but the course of the disease results in respiratory and cardiac failure. ${ }^{3}$ The incidence of $\mathrm{BD}$ has been reported in at least 1 in 18,450 male live births, ${ }^{4}$ and patients usually die before they are 20 years old due to respiratory or cardiac reasons. There are limited data about anesthetic management challenges for anesthesiologists in patients with BD due to malignant hyperthermia, rhabdomyolysis and hyperkalemia. ${ }^{5,6} \mathrm{It}$ appears that resistance to non-depolarizing neuromuscular blockers occurs due to reduced sensitivity of fetal nAChRs to competitive antagonists, but clinically the reverse of the event can be observed. Patients with myopathy show unusual sensitivity to non-depolarizing neuromuscular blockers. There is a high incidence of malignant hyperthermia in patients with myopathies and an association of rhabdomyolysis with the use of volatile anesthetics (VA). ${ }^{7}$ Insufficient evidence exists for the confirmation of BD and malignant hyperthermia (MH) association, which has led to anesthesia-inducing rhabdomyolysis (AIR). In addition, indirect evidence suggested that lack of dystrophin was the main reason for rhabdomyolysis after anesthesia with VA. This means that an older patient with BD is at risk of AIR due to their low muscle mass. ${ }^{8}$ Avoidance of potent VA and possibly propofol may help to reduce rhabdomyolysis, but it cannot eliminate it; however, other alternative drugs increase undesired reactions. ${ }^{9}$ The American College of Chest Physicians and the American Academy of Pediatrics stated (on consensus) that VA correlate with the risk of malignant hyperthermia-like reactions in persons with Duchene dystrophy because of their potential for cardiac arrest and sudden death. Therefore, the obvious approach is
Correspondence: Haleh Farzin Anesthesiology Department, Tabriz University of Medical Sciences, Shohada Teaching Hospital, 3I Danesghah Avenue, Tabriz, East Azerbaijan, Iran

Tel +989142574658

Email farzin.haleh@gmail.com 
avoidance of inhaled anesthetics for these patients. A total intravenous anesthetic technique was recommended in this study. ${ }^{10}$

The authors could not find any definitive report survey about anesthesia management in adult patients with BD. Here, the authors report a 43-year-old man with BD who underwent orthopedic surgery.

\section{Case report}

A 43-year-old man (weight: $80 \mathrm{~kg}$; height: $174 \mathrm{~cm}$ ) with BD was referred to the Department of Orthopedic, Shohada Teaching Hospital, for repair of patella fracture and patella tendon tearing after falling. He was not a child of parents who have familial relations and he has a disabled brother who is still alive. The patient was diagnosed at the age of 17 years, when he could not do standard exercise due to leg weakness. The diagnosis was made by completing a muscle biopsy. He required a cane for walking or sometimes a wheelchair. He was a goldsmith, but can no longer work. The patient underwent a procedure for inserting a KÜNTSCHER intramedullary rod in the femur 7 years ago and fixation of femur fracture 4 years ago, and he also received $20 \mathrm{mg} /$ day of prednisolone (at irregular intervals, based on the physician's recommendation). The disease did not affect other members of his family. The myopathy affected him in his right side, making him unable to move his right thigh. The patient could walk for $\sim 100-500 \mathrm{~m}$, when he followed a good nutrition plan. Upon physical examination, he had hypoesthesia in the right foot and severe swelling in the right knee but was conscious and oriented. The patient had stable vital signs, and auscultation of the heart and lungs did not reveal any murmur or additional sounds. The laboratory test results were as follows: hemoglobin $(\mathrm{Hb})$ : $13.6 \mathrm{~g} / \mathrm{dL}$, hematocrit (Hct): 41.1\%, white blood cells (WBC) count: $12.1 / \mathrm{mm}^{3}$, platelet count: $211,000 / \mathrm{mm}^{3}$, international normalized ratio (INR): 1, prothrombin time (PT): 13 seconds, partial thromboplastin time (PTT): 38 seconds, plasma blood urea nitrogen (BUN): $19.5 \mathrm{mg} / \mathrm{dL}$ and creatinine: $0.9 \mathrm{mg} / \mathrm{dL}$, blood group: $\mathrm{ARH}+$, potassium: $4 \mathrm{mg} / \mathrm{dL}$ and blood sugar: $71 \mathrm{mg} / \mathrm{dL}$. Cardiologist and internist consultations revealed that he had no heart problems, and echocardiography was normal (ejection fraction [EF]: 60\%, normal chamber size, absence of pulmonary hypertension, absence of pericardial effusion, left ventricular systolic diameter [LVSD]: 4.2 and right ventricular diastolic diameter [RVDD]: 2.2).

Electrocardiography was normal (sinus rhythm), and it was recommended that the procedure should be performed under general anesthesia.

On the day of the operation, the patient fasted for 8 hours and was hydrated with $400 \mathrm{~mL}$ ringer solution. Accordingly, in the operation room, the patient was monitored by routine standards (heart rate: $89 \mathrm{bpm}$, blood pressure: $133 / 86 \mathrm{mmHg}$, respiratory rate: $12 / \mathrm{min}, \mathrm{SpO}_{2}: 100 \%$ and body temperature: $37.3^{\circ} \mathrm{C}$ axillary). A total of $200 \mathrm{mg}$ hydrocortisone was injected as the stress dose, and the total intravenous anesthesia (TIVA) technique was used. The patient was in the supine position and he was preoxygenated by $6 \mathrm{~L} / \mathrm{min} \mathrm{O}_{2}$ over 3 minutes via an anesthesia face mask. Induction of anesthesia was performed with $2 \mathrm{mg}$ midazolam, $250 \mu \mathrm{g}$ remifentanil and $60 \mathrm{mg}$ lidocaine $2 \%$. For maintenance of anesthesia, $200 \mathrm{mg}$ of propofol was administered, and the patient was intubated with endotracheal tube (ETT) size 8; $3 \mathrm{~L} / \mathrm{min}_{2}, 3 \mathrm{~L} / \mathrm{min}_{2} \mathrm{O}$ and $0.5 \%$ isoflurane were then discontinued. Furthermore, 75-100 $\mu \mathrm{g} / \mathrm{kg} / \mathrm{min}$ propofol and $0.05-2 \mu \mathrm{g} / \mathrm{kg} / \mathrm{min}$ remifentanil were infused using a syringe pump until termination of the operation, which lasted 90 minutes. No muscle relaxant or nerve stimulator was used. End tidal carbon dioxide was measured by side stream capnography $(30-35 \mathrm{mmHg})$. The patient was safely extubated after surgery and transferred to the post-anesthesia recovery unit. In Post Anesthesia Care Unit (PACU), the patient was routinely monitored for apnea symptoms. Urine was examined for rhabdomyolysis-induced myoglobinuria. The vital signs at this time were as follows: heart rate: $87 \mathrm{bpm}$, blood pressure: $108 / 74 \mathrm{mmHg}$, respiratory rate: $12 / \mathrm{min}, \mathrm{SpO}_{2}: 100 \%$ and body temperature: $37.5^{\circ} \mathrm{C}$ axillary. No adverse event was recorded during surgery and anesthesia. Antibiotics comprising of cefazolin $1 \mathrm{~g}$ intravenously every 6 hours and gentamicin $240 \mathrm{mg} / \mathrm{stat}$ (one dose) were administered over a 24 -hour period. All laboratory tests were repeated and showed results were within normal range, and the patient was discharged after 72 hours of operation. The patient was called 3 months after surgery; he does not experience any new alteration in his general condition and continues to receive the same care that he did pre-surgery.

The authors obtained written informed consent for the publication of this case report.

\section{Discussion}

Here, the authors describe the anesthetic challenge in an adult patient with BD undergoing orthopedic surgery. BD is a muscle congenital disorder resulting in respiratory and cardiac insufficiency. BD is a rare disease affecting very young men, ${ }^{3}$ hence, the authors cannot find other new cases of adults with BD undergoing anesthesia, especially in their region. Poole et $\mathrm{al}^{11}$ reported unpredictable cardiac arrest after anesthesia with isoflurane; the patient underwent cardiopulmonary resuscitation (CPR) and recovered without any adverse events on functional or cognitive levels. Furthermore, additional investigations showed that the patient had BD. In 
1976, one case study was conducted on 67 patients with mild BD. This disease manifests itself by progressive proximal myopathy. These patients had no evidence of electrocardiogram (ECG) abnormalities due to the mild course of BD. Mild BD has a late onset, the patients depend on wheelchairs after 20-30 years of age, and the average life expectancy is slightly decreased. In Emery and Skinner's study, 17 cases (8-44 years old) were mobile and alive. ${ }^{12}$

We have stated that one of the important considerations in $\mathrm{BD}$ is the avoidance of hyperkalemia and malignant hyperthermia. Our patient underwent anesthesia two times without any marked problem. Overall, TIVA by modern short-acting anesthetic agents and non-depolarizing muscle relaxants, and occasionally newer VA, such as desflurane and sevoflurane, can promote recovery and result in reducing post-operative complications. ${ }^{6}$ Pre-existing neuromuscular disease is a particular challenge for anesthesiologists and many of them prefer general anesthesia versus regional anesthesia, despite controlled studies on regional anesthesia in myopathies. ${ }^{13} \mathrm{We}$ can perform neuraxial techniques (eg, epidural catheters) in special patients with myopathy for pain control and reduce sedation and respiratory depression. However, patients with Duchene dystrophy are prone to postoperative congestive heart failure, dysrhythmia, and inadequate cardiac output. It seems that transfusions and intravenous fluid administration induce fluid shifts. ${ }^{7}$ Short time usage of VA is a good option for intubation, but most anesthesiologists would switch to TIVA for the continuation of the surgery. Clinicians should monitor subjects who are exposed to volatile agents for signs of rhabdomyolysis, whose risk is not eliminated even with monitored anesthesia. ${ }^{14}$

One survey concluded that using volatile agents for anesthetic technique in patients with myopathy was acceptable if the anesthesiologist performs this work with great caution and monitors vital signs, urine color, electrolytes and blood gas sampling. ${ }^{15}$

Milne and Rosales ${ }^{16}$ reported one patient with BD undergoing spinal fusion surgery. This patient did not experience any complications of anesthesia in surgery.

Milne and Rosales ${ }^{16}$ stated that preoperative evaluation and preparation tests (need for wheelchair, assessment of systemic symptoms and signs, electrolytes, occult cardiomyopathies and mobility problems, drug history, family history and disabilities history) with cardiac status evaluation and consultation with a cardiologist and internist can result in proper choice of anesthetic agents. Careful postoperative monitoring can contribute to safe anesthesia. ${ }^{17}$ Driessen et al ${ }^{18}$ opined that profound understanding of genetic pathophysiology and the clinical course of neuromuscular disorders can help to decrease serious anesthesia complications. ${ }^{18}$

\section{Conclusion}

To manage anesthesia in patients with BD undergoing surgery, we preferred TIVA anesthesia in order to avoid agents which can cause rhabdomyolysis-induced myoglobinuria, malignant hyperthermia and hyperkalemia.

\section{Disclosure}

The authors report no conflicts of interest in this work.

\section{References}

1. Emery AE. The muscular dystrophies. Lancet. 2002;359(9307):687-695.

2. Koenig M, Beggs A, Moyer M, et al. The molecular basis for Duchenne versus Becker muscular dystrophy: correlation of severity with type of deletion. Am J Hum Genet. 1989;45(4):498.

3. Spehrs-Ciaffi V, Fitting JW, Cotting J, Jeannet P-Y. Respiratory surveillance of patients with Duchenne and Becker muscular dystrophy. J Pediatr Rehabil Med. 2009;2(2):115-122.

4. Kaspar RW, Allen HD, Montanaro F. Current understanding and management of dilated cardiomyopathy in Duchenne and Becker muscular dystrophy. J Am Acad Nurse Pract. 2009;21(5):241-249.

5. Segura LG, Lorenz JD, Weingarten TN, et al. Anesthesia and Duchenne or Becker muscular dystrophy: review of 117 anesthetic exposures. Pediatr Anesth. 2013;23(9):855-864.

6. Klingler W, Lehmann-Horn F, Jurkat-Rott K. Complications of anaesthesia in neuromuscular disorders. Neuromuscul Disord. 2005;15(3):195-206.

7. Naguib M, Flood P, McArdle JJ, Brenner H. Advances in neurobiology of the neuromuscular junction implications for the anesthesiologist. J Am Soc Anesthesiol. 2002;96(1):202-231.

8. Hayes J, Veyckemans F, Bissonnette B. Duchenne muscular dystrophy: an old anesthesia problem revisited. Pediatr Anesth. 2008;18(2):100-106.

9. Hopkins PM. Anaesthesia and the Sex-Linked Dystrophies: Between a Rock and a Hard Place. Oxford: Oxford University Press; 2010.

10. Birnkrant DJ. The American College of Chest Physicians consensus statement on the respiratory and related management of patients with Duchenne muscular dystrophy undergoing anesthesia or sedation. Pediatrics. 2009;123(suppl 4):S242-S244.

11. Poole T, Lim T, Buck J, Kong A. Perioperative cardiac arrest in a patient with previously undiagnosed Becker's muscular dystrophy after isoflurane anaesthesia for elective surgery. Br J Anaesth. 2010;104(4): 487-489.

12. Emery AE, Skinner R. Clinical studies in benign (Becker type) X-linked muscular dystrophy. Clin Genet. 1976;10(4):189-201.

13. Vercauteren M, Heytens L. Anaesthetic considerations for patients with a pre-existing neurological deficit: are neuraxial techniques safe? Acta Anaesthesiol Scand. 2007;51(7):831-838.

14. Zheng-Ward F. Duchenne muscular dystrophy and anesthesia. Proc UCLA Health. 2017;21.

15. Gronert GA. Cardiac arrest after succinylcholine mortality greater with rhabdomyolysis than receptor upregulation. Anesthesiology. 2001;94(3):523-529.

16. Milne B, Rosales JK. Anaesthetic considerations in patients with muscular dystrophy undergoing spinal fusion and Harrington rod insertion. Can Anaesth Soc J. 1982;29(3):250.

17. Cripe LH, Tobias JD. Cardiac considerations in the operative management of the patient with Duchenne or Becker muscular dystrophy. Pediatr Anesth. 2013;23(9):777-784.

18. Driessen JJ. Neuromuscular and mitochondrial disorders: what is relevant to the anaesthesiologist? Curr Opin Anesthesiol. 2008;21(3):350-355. 
International Medical Case Reports Journal

Dovepress

Publish your work in this journal

The International Medical Case Reports Journal is an international, peer-reviewed open-access journal publishing original case reports from all medical specialties. Previously unpublished medical posters are also accepted relating to any area of clinical or preclinical science. Submissions should not normally exceed 2,000 words or

4 published pages including figures, diagrams and references. The manuscript management system is completely online and includes a very quick and fair peer-review system, which is all easy to use. Visit http://www.dovepress.com/testimonials.php to read real quotes from published authors.

Submit your manuscript here: https://www.dovepress.com/international-medical-case-reports-journal-journal 